\title{
EL HUMOR EN LA NARRATIVA DE GRACIELA HUINAO*
}

\author{
AN ANALYSIS OF THE ROLE OF HUMOR IN GRACIELA \\ HUINAO'S NARRATIVE \\ Damsi Figueroa Verdugo \\ Universidad de Concepción. Concepción. Chile. \\ damsifv@gmail.com
}

\begin{abstract}
Resumen: Este ensayo explora distintas manifestaciones y funciones que asume el humor en tres libros de Graciela Huinao: La nieta del brujo (2014 [2003]), Desde el fogón de una casa de putas williche (2010) y Katrilef, hija de un ulmen williche (2015). Dentro de la prolífica y necesaria escritura de autores mapuche, la obra de Graciela Huinao se caracteriza de manera especial por utilizar el humor como clave dentro de su proyecto poético mayor. El humor es fundamental en el proceso de sanación del alma de su pueblo herido por la guerra y las formas que este adopta son tan diversas y complejas que nos remite a temas y formas literarias de tiempos disímiles, que coexisten de manera polémica, enriqueciendo el imaginario literario intercultural mapuche-chileno en la actualidad.
\end{abstract}

Palabras clave: Graciela Huinao, nueva narrativa mapuche, humor en la literatura mapuche, lectura intercultural.

\begin{abstract}
This essay explore the different manifestations and functions humor adopts in three books by Graciela Huinao: La nieta del brujo (2014 [2003]), Desde el fogón de una casa de putas williche (2010), and Katrilef, hija de un ulmen williche (2015). Within the prolific and necessary writing by Mapuche authors, Huinao's work is distinctly characterized by the use of humor as a key element of her larger poetical body of work. Humor is an essential part in the healing process of her people's soul wounded by war, and the forms it adopts are so diverse and complex which take us to
\end{abstract}

* Esta investigación forma parte de la tesis de doctorado en Literatura latinoamericana (Universidad de Concepción, Chile) en proceso: "Poéticas mapuche, lecturas interculturales"; financiada por la Comisión Nacional de Investigación Científica y Tecnológica, Conicyt. 
themes and literary forms from diverse times, which controversially coexist nurturing the current intercultural Chilean-Mapuche literary imaginary.

Keywords: Graciela Huinao, Mapuche contemporary narrative, humor in mapuche literature, intercultural literature, intercultural reading.

Recibido: 10.01.2017. Aceptado: 01.05.2018.

$\mathrm{L}$ A NUEVA NARRATIVA MAPUCHE ${ }^{1}$ está conformada por Ruth Fuentealba Millaguir (2008), Graciela Huinao (2014 [2003], 2010, 2015), Miguel Ángel Antipan Curín (1997), Pablo Ayenao (2015), Javier Milanca Olivares (2015) y Marcos Huaiquilaf (2006, 2016). Realizar una lectura intercultural de la literatura mapuche actual implica observar cómo junto a las formas contemporáneas de la novela, el cuento, el relato breve y la poesía, coexisten de manera imbricada otras formas artísticas que tienen su origen en la tradición oral. Estas otras narratividades encuentran en el epew su forma artística más difundida. Así comprendida, el humor no está ausente en la literatura mapuche, tiene una presencia importante; que actualiza la relevancia del humor en la sociedad mapuche tradicional ${ }^{2}$. Cabe destacar la presencia del humor en el conjunto de epew publicado por Antullangka (2009), en la obra poética de Aillapán (2005), en Aniñir (2014, 2009, 2008), en los relatos del premiado libro Xampurria de Javier Milanca (2015) y en la reciente obra de Marcos Huaiquilaf (2016), Receta para engendrar un varón; y, si ampliamos nuestra concepción del humor a una actitud lúdica frente a la vida expresada en los juegos del lenguaje poético, no podemos dejar de reconocer la presencia de la alegría y del juego en la poesía de María Teresa Panchillo (2010), María Cecilia Nahuelquín (s/f) y Bernardo Colipán (2005).

${ }^{1}$ Carrasco (2010), García (2011) destacaron por primera vez la emergencia de una nueva narrativa mapuche, caracterizada por una apropiación de las formas modernas del cuento y la novela. El presente ensayo amplía el registro de autores realizado entonces y hace operar sus principales observaciones generales, la hibridez textual y el enfoque histórico de las narraciones, en el análisis del humor en la obra de Graciela Huinao.

${ }^{2}$ La valoración del humor en la cultura mapuche, entendido como una actitud de constante celebración de la vida, se puede observar en los pasajes que construye Manquilef en sus Comentarios Araucanos (2006 [1911]), para retratar su cultura, donde la convivencia festiva aparece como base de la integración social mapuche. 
Dentro de este conjunto mayor, la obra de Huinao ${ }^{3}$ destaca por varios aspectos. Primero, es el primer proyecto escritural de una mujer mapuche cuyo trabajo constituye una obra propiamente tal, compuesta, y si nos limitamos solo a la narrativa, de tres títulos: La nieta del brujo (2014[2003]), Desde el fogón de una casa de putas williche (2010) y Katrilef, hija de un ülmen williche (2015). Iván Carrasco (2014: 117) ha señalado que Cherrufe. La bola de fuego de Ruth Fuentealba Millaguir y Desde el fogón de una casa de putas williche de Graciela Huinao "pueden considerarse las primeras escrituras novelescas mapuche escritas en español". Ambas tienen por objetivo central dar cuenta de sucesos históricos desencadenados a partir de "la maldita guerra"... "La conquista militar por Chile de los Mapuche del Gulumapu (que) entra en acción el año 1862 cuando de acuerdo al plan del coronel Cornelio Saavedra había que avanzar la frontera del Biobío al Malleko" (Marimán, 2006: 102). Una literatura que tiene como tema central la memoria del sufrimiento y el despojo de un pueblo pareciera no dejar espacio para el humor, sin embargo, la maestría de Huinao logra otorgarle un lugar fundamental.

Graciela Huinao construye una poética que caracteriza y otorga unidad a toda su obra. Podemos acceder a ella primeramente a través de la declaración de la autora como poseedora de una actitud frente a la vida que se nutre del humor, esa "malicia de mujer originaria" (Huinao, 2015: 3), que le ha permitido "doblar la mano al destino", logrando superar una vida de carencias para transformarse en la reconocida escritora que hoy día es. Esta actitud de confianza, unida a un profundo respeto y lealtad por su cultura y sus antepasados está en el centro de su poética, y es donde se sustentan todas las manifestaciones humorísticas en su obra: “...Y sigo tratando de caminar lentamente para no perder el equilibrio. Sabiendo que debo saltar

${ }^{3}$ El trabajo poético de Graciela Huinao ha sido ampliamente reconocido. En forma individual publicó Walinto (2009a). La presencia de su poesía en antologías de poesía mapuche es permanente, entre las que cabe destacar Hilando en la memoria (2006) e Hilando la memoria II (2009b), donde además trabajó como co-editora. Su ejercicio escritural se ve complementado por un intenso trabajo como gestora y difusora de la cultura tradicional mapuche, desempeñándose como transmisora del rakizuam y el kimün en diversas instancias de educación, como talleres, intervenciones en mesas de diálogo y lecturas poéticas en diversos festivales de poesía y conferencias en universidades chilenas y extranjeras. El amplio espectro de su labor como creadora y difusora cultural le ha valido su incorporación a la Academia Chilena de la Lengua. 
muchas vallas y más de una vez trastabillaré. Pero agarrada a la fuerza de mis antepasados, ni el moho de la vida, que empieza a amenazar mis huesos me detendrá"... "qué importa si vamos desbocadas por la vida, y si alguna vez logramos una madurez, esta será obtenida tras las zancadillas que nos hizo la vida y lo más importante: este espíritu porfiado que mis abuelas tejieron en mi conciencia y que a veces me sirve para simular ser feliz". En estas palabras del Prólogo de Desde el fogón de una casa de putas williche, Huinao se identifica con la fuerza silenciada e incomprendida de las mujeres protagonistas de su novela. Huinao escribe desde su "conciencia obrera mapuche" (2010: 11), ahí está la fuerza que le impone reunir, a modo de nüxram ${ }^{4}$ en una "junta" o trawun ${ }^{5}$ las voces presentes y pasadas que transmiten la memoria histórica y la sabiduría de su pueblo:

Mi madre, nuestros abuelos escriben sus cuentos en este libro, si logro hacer que sus páginas hablen por ellos, que puedan escuchar sus voces y la voz de mi pueblo, La nieta del brujo habrá cumplido su tarea. Porque realmente se necesita ser bruja para romper la barrera de la discriminación en esta tierra... Por estas grandes y pequeñas cosas quiero que conozcan mi pueblo. Su historia, que ha sido contada siempre por el enemigo, es tiempo de conocer la "voz de la gente de la tierra". Si hoy, estas páginas no dicen nada, soy una mujer de fe, las futuras generaciones con seguridad entenderán "El hablar de la tierra" (Huinao, 2014: 6).

Aquí leemos la reafirmación de una concepción de escritura como reunión de las voces de la gente de la tierra que configuran una historia contada desde la visión mapuche; a través de una nueva narratividad que cuenta la historia

${ }^{4}$ Sobre epew y ngütram Salas (2006: 328) señala "El epeo es una narración tradicional de ficción, no cualquier narración; el ngütram es, en el nivel de máximo contraste, narración tradicional estipulada como histórica, de modo que epeo y ngütram contrastan como relato ficticio (cuento), opuesto a relato no ficticio (historia). El gnütram tiene un nivel más específico de distinción: El perimontun o "visión", que es un relato estipulado como histórico, que contiene elementos mágicos y míticos”. Mansilla (2006 [2001]) utiliza este concepto para referirse a la estrategia discursiva mapuche que asume Jaime Huenún (42) para elaborar el universo lírico del libro Ceremonias (1999) y define "Nütrum es un tipo de conversación mapuche en que se entrelazan, en un mismo nivel de discurso, relatos de sueños, visiones del más allá (del cielo de arriba), del pasado remoto y de hechos de la vida cotidiana actual" (Nota al final del ensayo, 46).

${ }^{5}$ El Xawün, reunión mapuche, un espacio vital para la transmisión y validación del discurso histórico, para traducirse en poderoso elemento de cohesión social (Millalén, 2006: 26). 
silenciada, la otra historia, que deben conocer las generaciones presentes y las por venir. En este punto es posible relacionar el papel de la escritura en el contexto actual con las antiguas juntas o trawun:

El objeto del Parlamento o "junta" como se denomina a estas reuniones en lenguaje mapuche, fue especialmente el de comunicarse los caciques entre sí, y referirse mutuamente los infortunios que padecen; contarse en familia, digámoslo así, los inauditos atropellos que los "españoles" cometen contra ellos, oír las opiniones de los ancianos, a los cuales guardan profundo respeto y resolver de mancomún lo que, a juicio de todos sería conveniente hacer para poner a salvo lo que les resta de su patria antes libre: su tierra, su ruca, sus animales (Díaz, 2006 [1907]: 16).

Hoy Huinao abre a través de la literatura el círculo comunicativo intracultural de la junta o trawun, en un nuevo contexto histórico, como vehículo comunicante que deja abierto el espectro de su recepción, asumiendo el carácter intercultural de su escritura, como arte contemporáneo, que llega a lectores mapuche, niños y jóvenes, así como a un público general interesado en esta nueva narratividad ligada a la cuestión mapuche, dentro y fuera del país, con el claro objetivo de comunicar, transmitir, difundir la cruda realidad del despojo del que ha sido víctima su pueblo, pero también amplificar la fuerza y la sabiduría que le ha permitido proyectarse en el camino de la autonomía y la autodeterminación.

En la obra de Huinao, las voces de sus ancestros, por línea materna y paterna, su ascendencia, configuran la fuente de autoridades que han transmitido el kimün, o sabiduría mapuche ancestral, a todo su linaje. Lugar fundamental tiene en la educación mapuche de la niña Huinao, dentro del relato del libro homónimo La nieta del brujo, su abuelo Juan, cuyo nombre verdadero debió haber sido Ayuwun (sonriente): "Mi abuelo materno nació con una sonrisa tatuada. No era una carcajada, sino una sonrisa de niño jugando en ese rostro anciano... Los antiguos siempre buscaban un nombre apropiado al nacer, tengo la convicción de que su primer nombre pudo haber sido Ayuwun" (Huinao, 2014: 36). Esta revelación, del verdadero nombre ${ }^{6}$ del abuelo, signa el vínculo inalienable entre humor y sabiduría. "Allí estaba (2007).

${ }^{6}$ Sobre la importancia del nombre propio en la cultura mapuche ver Durán; Catriquir 
mi abuelo... Y me largué a reír. Me reí casi hasta el dolor de guata. Mi abuelo tenía una carreta sin ruedas. La curiosa risa empezó a buscar por los alrededores las ruedas... luego de andar un rato, la risa se convirtió en un curioso entendimiento" (Huinao, 2014: 39). El humor está en la base del kimeltun o kimeltuwun, el sistema de educación tradicional mapuche. Aquí el humor es expresión de confianza, empatía, entendimiento en un plano superior de relación fundamentada en el amor.

En el primer relato del libro La nieta del brujo, "La gitana del Tabón", Huinao escudriña en los orígenes de su linaje. Filomena Santana, su tatarabuela, es rescatada de un naufragio y acogida por un grupo de familias canoeras de los fiordos del extremo sur. La gitana del Tabón, como será llamada más tarde, vivió sin memoria y sin nombre por largo tiempo, afectada de una amnesia que parecía irrecuperable, hasta que el amor que creció entre ella y un curandero selk'nam que la sanó con el propio calor de su cuerpo, la hizo volver definitivamente a la vida. Chaura era su nombre, tomado de una hermosa flor patagónica, símbolo también de alegría: "Dura y serena su mirada oriental, la risa lo cegaba, ya que cerraba los ojos casi completamente al reír" (Huinao, 2014: 16). La risa no estuvo ausente en este proceso de sanación. Para los curanderos, la sanación del cuerpo está directamente relacionada con el bienestar del alma, ellos eran también los chamanes que conservaban y transmitían los saberes sagrados que mantenían en equilibrio la vida humana con las energías sagradas de la tierra. "En Indoamérica el sentido de la risa y el humor se asoció al esplendor de la vida con explícitas resonancias sagradas... Las culturas guaraníes y mapuches confirman el vigor y la importancia del buen humor, la alegría y la risa en Indoamérica del sur" (Salinas, 2010: 16). Dentro de la misma serie de relatos, en "Palle", vuelve a florecer la imagen del curandero que sana con su alegría y perseverancia: "El abuelito Palle fue un médico natural, conocido en los pueblos indígenas del sur, que curaba las heridas del cuerpo como el mejor cirujano de hoy, no solo eso tuvo que curar, después del genocidio de la guerra, el espíritu de mi pueblo quedó herido, dio su vida tratándolo de sanar" (Huinao, 2014: 34).

En la novela Katrilef, hija de un ulmen williche, Huinao retoma este tema, pero esta vez en una figura basal de la estructura política y religiosa de su pueblo: el machi. La novela relata la cruda historia de los años inmediatamente posteriores a la ocupación militar encabezada por el coronel Cornelio Saavedra, que significó para la nación mapuche una nueva forma de guerra 
unilateral donde actuarían colonos chilenos y extranjeros, hacendados, la iglesia y estado organizados y arremetiendo no solo con el fusil sino con una nueva arma: la escritura" (Huinao, 2014: 31, 116, 117, 162); instrumento mediante el cual se despojaría de todas sus riquezas a los grandes ulmenes del sur, obligándolos a refundar sus comunidades en reducciones que tuvieron que comprar y pagar con la sangre de sus propios hijos y mujeres. La novela narra la historia de la niña Katrilef, y de cómo en su proceso de transformación de niña a mujer logra cambiar a su vez las normas políticas, o Ad mapu, que afectan a la mujer mapuche manteniéndola subordinada a las necesidades de la guerra. Esta es la verdadera transgresión y rebeldía de la heroína de la novela: "Siempre supo (la niña Katrilef) que la historia de su pueblo era una larga cadena de guerras... por el traspaso oral de sus abuelas ella se enteró que por más de tres centurias la resistencia del vientre de las mujeres mapuche fue esencial para el aguante de esta prolongada guerra” (Huinao, 2014: 23).

Antes de su matrimonio forzado, la aún niña Katrilef traspasa las barreras culturales que separaban a las mujeres del ámbito político, al dialogar con el machi de su comunidad, el mismo que sellaría en oficiosa sacralidad la violación de la niña por su marido desconocido. Este primer acercamiento entre la niña Katrilef y el machi, está signado nuevamente por la sonrisa como aproximación cómplice de dos almas que se comprenden y se respetan, más allá de la cruda realidad que les impone la tradición: "(La niña Katrilef) no se restringió ante la autoridad que representaba la figura del machi, porque sus palabras siguieron como si conversara con un gran amigo. Una singular sonrisa del machi a ella le entregó un poco de claridad a sus negras dudas"... "Los labios de ella se rindieron al rictus amargo, las palabras del machi hicieron que ambos esbozaran leves sonrisas, la pócima del médico estaba empezando a hacer efecto: sanar la reciente herida de su alma que su pronto casamiento le había producido" (Huinao, 2014: 28).

Este primer acercamiento a través de la sonrisa abre un nuevo camino para Katrilef y para todas las mujeres de su pueblo. Hasta entonces:

Las leyes de su pueblo decían que ella debía pasar una noche de prueba: ensayo que todas las mujeres temían, ya que si el comprador no estaba contento con el producto, poseía la facultad de devolverlas tras su uso, argumentando su descontento carnal y nadie ponía en tela de juicio la palabra de un hombre insatisfecho (...). Su violación disfrazada por una 
tradición cultural se consumó cumpliendo las reglas milenarias de su pueblo... su ley decía que para respetarla y cumplirla había nacido" (38-39).

Cruda realidad que Katrilef logra transgredir conformando un nuevo orden, cuando decide casarse, por segunda vez, y esta vez, por propia voluntad bajo la ley del amor. Katrilef logra, a través del desarrollo de la novela, una serie de transformaciones al ad mapu, a favor de las mujeres de su pueblo. Actúa guiada por la solidaridad hacia aquellas mujeres que, de no ser por sus acciones, hubieran muerto en el desprecio y abandono de su propia comunidad: ese era el destino que esperaba a la mujer "devuelta", de bello nombre Wanglen, que significa estrella y cuyo rol en los relatos cosmogónicos no es otra cosa menos que la niña venida del cielo de cuya sangre emerge toda la vida sobre la tierra (Marileo, 2007). Gracias a la influencia de Katrilef, la mujer devuelta se tranformó en consejera de la joven, llegando a ocupar un lugar importante en la familia del ulmen Katrilef. La transgresora solidaridad de Katrilef alcanza a la mujer chilena, su cuñada, llamada por todos de manera despreciativa La Winka, que compartía con el hermano de Katrilef no solo el amor, sino también el desarraigo de su propia identidad cultural. En cada una de sus acciones Katrilef encuentra fuerza en una actitud vital, alegre, confiada, en la naturaleza y en la profundidad de sus creencias espirituales, así como en una inalienable convicción de género. La sonrisa es parte de la expresividad de un diálogo horizontal entre hombres y mujeres, con serias connotaciones políticas.

El humor, en los relatos y novelas de Huinao, cumple funciones diversas. Si la sonrisa es la herramienta comunicativa que puede dar paso a la confianza y el entendimiento, así como la fuente desde donde emana la fuerza vital de todo proceso de sanación del cuerpo y del alma, la carcajada cumple una función muy distinta, y no menos efectiva, en el proceso de ruptura de las estructuras hegemónicas que rigen el discurso oficial, histórico, religioso, político, etnográfico. Si la sonrisa, como gesto comunicativo, induce procesos de transformación individuales y colectivos, la carcajada logra romper en un acto brevísimo (Bergson, 2016), en un gesto de completa irreverencia, el orden político que ostenta la cultura dominante a través de sus dos principales aparatos de poder: la iglesia y la institución educativa. En "Trawun", el último de la serie de relatos La nieta del brujo, el tono de la narración se 
vuelca por completo hacia lo cómico. Una irónica descripción abre el relato; todo transcurre en el pacífico pueblo de Riachuelo ${ }^{7}$ :

En un lado la iglesia, en el otro el calabozo...curiosamente vacío...La iglesia era la más destacada...se había adjudicado el mejor terreno. Tres calles era todo el pueblo, distribuido de tal manera que nada sobrara o faltara. Una escuela..., con su cantina al lado, no para fomentar el alcoholismo, sino por una cosa cultural, los alumnos en su mayoría eran mapuche... un cuartel de bomberos, nunca habían apagado un incendio... los incendios allí nunca fueron imaginados, porque el carro era tirado por "rápido" y "ligero"... una Cruz roja, sin camas, remedios, ni doctores, simplemente casi nadie se enfermaba y cuando alguien lo hacía, la machi lo arreglaba (48).

La ironía consiste en que este orden "perfecto" donde no hay incendios ni enfermos, ni delincuentes, solo puede ser sostenida gracias a que sus habitantes se rigen "por una obsoleta ley: el diálogo, en sus trawun”. El motivo que moviliza la acción en este pueblo donde nunca pasa nada es la muerte del "cura gordo y bonachón" que vino a morir con "las limosnas entre las manos". En pleno invierno, aislado el pueblo por las lluvias y derrumbes, no había cómo "avisar a la iglesia mayor" para que vinieran a enterrar al cura: "En secreto se realizó el trawün, para no espantar al muerto, importantes puntos se debatieron para el entierro. El carpintero del pueblo fabricó el ataúd... se sacrificó el árbol más antiguo de la comunidad... al principio quedó como un bote, más tarde no tenía forma, ya que todo el pueblo había pegado un hachazo bajo el calor de unos tragos de vino para espantar el frío" (50). El tema del cura usurero, tradicional en la literatura (Salinas, 2010: 70), es para Huinao un recurso que permite construir un universo narrativo donde los hombres de iglesia exhiben su avaricia y extrema inconsecuencia:

${ }^{7}$ Riachuelo era el nombre del sector donde el ülmen Katrilef, bisabuelo de Huinao, compró, luego de haber sido despojado de sus tierras ancestrales, para poder sostener la vida mapuche williche de su comunidad. Se llamó a esta nueva comunidad Loi-Katrilef de Walinto (Huinao, 2014: 162). Riachuelo debió haber sido el primer pueblo donde emigraron los parientes de Huinao al abandonar la comunidad Loy-Katrilef, según las páginas finales de la novela Katrilef, hija de un ülmen williche. Pueblo ubicado en Osorno, Región de Los Lagos, cerca de Río Negro, Chile. 
si este cura bonachón cobraba chancho por casorio, dos ovejas por bautizo y un vacuno por velorio, los tres curas que vendrían a reemplazarlo después de su muerte no se contentarían sino con violar a la mismísima belleza del pueblo, María, la esposa del mapuche Fermín.

Dos curas extranjeros y un monaguillo vinieron a reemplazar al fallecido cura usurero: "Llegaron de noche como ladrones, sin pedir permiso". El cura principal un alemán gringo, que al ver a las mujeres amamantar "dejaba caer de su boca un hilillo de baba". El cura del medio, un español raquítico de pálido rostro era "el limpia babas" y el tercero era el que tocaba la campana, "un ser fétido en alcohol, si le apretaban la nariz no caía moco sino vino"(52).

Tal había sido la devoción que profesaron a María que tenían la iglesia empobrecida, todo estaba en la casa de la irresistible mujer, las sillas, los chanchos y las acciones evangelizadoras de los curas se habían reducido a entonar monumentales cantos gregorianos en las elevadas eucaristías que dejaban "sin pestañear a los mapuches asistentes", incluida María. Muy pronto llegó de Santiago una comitiva de la iglesia a ordenar las cosas: "Un cura rubicundo y dos arcaicas señoritas, eran los cabeza de malón, el resto: lacayos políticos". La comitiva intentó sin éxito dar nueva y correcta sepultura al fallecido sacerdote; no se pudo dar con el lugar del entierro. "Dos reuniones hubo en el pueblo, una en la iglesia y la otra: trawün en casa de María. En la iglesia se les leyó la sentencia a los tres curas, dejarían el pueblo a la brevedad. La otra fue en Mapudungun para que solo los mapuche entendieran lo que se acordaba allí" (56). Solo al final del relato sabremos cuál fue el plan de los mapuche y es entonces cuando surge la carcajada en la boca del lector, que es la forma que usa Huinao para hacer justicia, es decir, dentro de la diégesis de la narración nadie se ríe de nadie, es el lector quien se verá asaltado por una carcajada burlesca, que humilla a los tres curas que representan los vicios de la iglesia, colocándolos/la en su lugar. La risa aquí devuelve el poder de hacer justicia y libera a los humillados.

El relato se mueve entre la comedia y el realismo. Los williche habían previsto que los curas ingresarían a la casa de María para violarla antes de abandonar el pueblo. María estaba preparada y los hombres volverían temprano de la minga: cada uno de los tres curas se desnudó mientras perseguían a oscuras a la mujer por toda la casa hasta que llegaron los mapuche del campo, 
el cura gringo saltó por la ventana cayendo sobre los perros, al español lo apalearon en la oscuridad, por tratarse de un espíritu malo...el campanillero, al ver a los indios alzados, desnudo se metió a un canasto de ropa...con la mala suerte que dejó el culo para afuera... Un mapuche que pasó al ver una superficie blanca y liza con un hoyo en el centro clavó una vela, para iluminar la pieza. Poco a poco la vela empezó a derretirse, ni un quejido, ni un llanto hasta que la vela se apagó. Y salió como un cohete, el cura disparado por el campo (57).

La lógica del relato impone, para que domine la imagen irónica del tranquilo pueblo de Riachuelo, que luego del episodio de la frustrada violación, todo continuara como si nada hubiese pasado. Es este ambiente de aparente apatía frente a los hechos el que permite el juego del humor, el humor como justicia en la boca del lector. La venganza sucede en el plano simbólico del relato, que contrariamente a lo poco serio de los hechos relatados encierra un sentido profundamente político. A través del trawun mapuche se resuelve que el ajuste de cuentas se constituirá en un acto público, donde la iglesia y el culto serán el espacio de confesión y de exposición de los pecados de los curas:

El pueblo esperaba de rodillas a sus guías wingka espirituales impuestos. El mordido de perro apareció primero, a los segundos el apaleado, y en tercer lugar el otro. En primera fila estaba María, más hermosa que nunca con Fermín a su lado. El pueblo con flores silvestres había arreglado el altar, el cáliz recién pulido conteniendo el mejor de los vinos. El cura gringo abrió los brazos, los dos curas hicieron lo mismo. El primer cura lanza al aire una canción, paseándose por todas las notas musicales, dejó en blanco los ojos y la baba corrió por entre sus labios y cantó:

-"Que linda está María-a-a-a-a”.

-Amén -contestó el pueblo.

- “Con la plata tuya y la mía-a-a-a”.

Contestó el cura español, en su empinadura más alta.

-"Y yo como no tenía dinero-o-o-o-o-o, mi culo sirvió de candelero". Nadie respondió.

AFI (58).

Hay aquí una inversión carnavalesca de los roles que busca el reacomodo de los valores de justicia y poder: es el pueblo quien juzga y los curas los sometidos a este juicio. Esta escena donde se parodia la liturgia católica contiene la ambivalencia regeneradora (Bajtín, 2003) necesaria para invertir el 
orden opresor. En este juicio a los curas en el espacio de la iglesia y a través de una parodia del canto litúrgico se genera una reapropiación de la autonomía y la autodeterminación en varios aspectos: del territorio expoliado por la Iglesia: la iglesia que "se había adjudicado el mejor terreno"; donde bien pudo haber estado anteriormente el espacio de reunión mapuche; pierde su carácter solemne de dedicación al culto y respeto a la autoridad del cura y sus ayudantes; es ahora el espacio del trawun; entendido como el ejercicio de unión del pueblo mapuche para resolver conflictos comunes. Mediante el secreto plan de los mapuche se restablece el equilibrio de los poderes que organizan la vida en el tranquilo pueblo de Riachuelo y la narración en complicidad con los personajes resuelve que será la carcajada del lector la que finalmente haga justicia.

En su libro La risa de Gabriela Mistral, Salinas (2010: 11) destaca cómo la poeta "supo comprender la risa burlesca de los indígenas ante los blancos". En su famoso ensayo "El tipo del indio americano" de 1932 señaló: "(las bocas indias) se levantan bruscamente en la risa burlona, dando una sorpresa a los que creen al indio tumbado en una animalidad triste".

En Desde el fogón de una casa de putas williche, Huinao elabora una visión crítica sobre el humor, colocándolo en el centro del conflicto intercultural:

Con su afafán (los williche) desataban la alegría enjaulada por el enemigo en los libros de historia que pueblan las casas de estudios y grandes bibliotecas. Esos baluartes de la historia y las ciencias definieron al pueblo mapuche como triste y monótono. Se cagaban de la risa los williche de estas aberraciones que se mantienen fehacientemente hasta el día de hoy ¿Cómo es posible que el sencillo gesto de la risa esté vedado en los pueblos originarios y que la felicidad tenga su cuna en el occidente? Aseveraciones distorsionadas como esas a los mapuche poco les importaba, sabían que la tristeza es un duro guerrero, que se debilita con una sonrisa y muere con un poco de felicidad (65).

Con estas palabras se inicia una secuencia narrativa de carácter explicativo-demostrativo, estructurado didácticamente ${ }^{8}$ a través de dos ejemplos:

${ }^{8}$ También se destaca la relación entre función didáctica y política en la literatura de Graciela Huinao en "The importance of poetry as didactic and Political Tool in Poems by Three Mapuche Poets" (Rubio, 2013). 
el epew intitulado "La Yehua y la Puma" y la canción, con ritmo de choikepurrün, "Zorras con zorras". Ambos textos logran derrumbar a golpe de carcajadas el mito del "indio triste" tan explotado por la literatura chilena y latinoamericana (Quevedo, 2000).

La carcajada en boca de los mapuche irrumpe en el orden de los discursos instituidos violentamente por el estado-nación chileno donde la iglesia y la escuela deben formar al mapuche en su proceso de inclusión. Aquí, donde el humor cumple una función específica de crítica al sistema de dominación, encontramos el epew kullin', o cuento de animales, "La yehua y la Puma". La rima asonante al final de las oraciones que introducen el relato, a modo de romance, es recurso mnemotécnico y estético, remite al origen oral e intercultural desde donde ha sido recreado, contexto en el que sin duda ha divertido a generaciones de mapuche que se ríen de la instrucción escolar y más específicamente de la figura de la profesora.

La forma cómica, con personajes altamente caracterizados, aspecto propio de la fábula, aporta al texto una potencialidad performativa para ser actuado o recreado en voz alta por el narrador metadiegético: Este narrador es Pichun, el mejor cliente de la famosa Trompa de pato:

Dicen que dijo el abuelo... y putas y clientes se arremolinaban alrededor del brasero: halagüeño o prepotente, valiente o cobarde, gentil o sumiso; sin importar el sexo, cada animal tenía su peculiar timbre de voz, que con maestría Pichun vocalizaba:

Hermosa era la yehua, de patas largas, de ancas firmes que junto a su potrillo en la pradera pastaba. Camuflada en medio de los matorrales una famélica puma la miraba. La cacería para la fiera había estado mala y ella era una madre pensante. ¿Cómo alimentar a tres cachorros hambrientos que en la montaña esperaban? Reflexionaba la puma entre la hierba: si me tiro con la yegua, capaz que me mate a patadas; tengo que meterle el diente al potrillo. iPero no se despega de su madre, el desgraciado! En tres tiempos, la puma elaboró un estratégico plan para alimentarse y ante la yegua se presentó:

-iBuenos días yegua!

La yegua se asustó con el saludo y preocupada caminó al lado de su cría, respondiendo con un movimiento de cabeza en salutación.

${ }^{9}$ Epew kullin es el título del próximo libro anunciado por Huinao; en proceso de publicación. 
-Lindo día -comentó la puma, mirando al potrillo que casi se acurrucaba bajo las patas de su madre.

-¿Anda de paseo, señora leona; por qué no está trabajando?- Por muy yegua que sea la yegua, no es güeona. De inmediato se dio cuenta que la puma traía malas intenciones.

La puma se arrastró por el suelo al empezarle a doler las tripas por el hambre, y de reojo miraba el pelaje hermoso del potrillo.

-Señora yegua -dijo la puma ocultando una maliciosa sonrisa-. He sido nombrada profesora de la montaña por el reino animal y ando buscando alumnos.

-Me alegro señora puma por su nuevo trabajo, así no tendrá que salir a matar para alimentarse

La yegua se dio cuenta que algo tramaba la puma.

-Señora yegua, es por eso que he venido a verla. Quizás... usted, mande a su potrillo a la escuela, yo lo llevo ahora y en la tarde se lo vengo a dejar... Y lo más importante, aprenderá a "leyer" y a "escribire".

Esta leona creerá que soy güeona, meditaba pastando la yegua.

-¿YY usted, señora puma, sabe leer y escribir?

-iPor supuesto! Soy “leia y escribia”, señora yegua -contestó la puma. Lamiéndose las garras.

La yegua sonrió y le dijo:

-Señora puma, no es que lo ponga en duda, le puedo hacer una prueba -lo dijo con cierto tono de inteligencia en la voz.

-iCómo no, señora yegua! -respondió de inmediato la puma, antes que se le escape la ocasión.

-Si fuera tan amable, señora puma, colóquese por la parte de atrás de mis ancas... por favor. La yegua prepara las ancas para levantar la cola y le pregunta.

-¿Qué dice ahí, señora leona?

La puma fijó la mirada sin pestañear en el culo de la yegua, luego se resfregó los ojos, puso la cabeza de lado para ver mejor...Y no se le escapaba ninguna sílaba, ningún sonido lograba descifrar. Al cabo de un rato y con una pequeña duda dijo:

-Parece "o", parece "i”.

Y iplaf! Por el aire la puma volaba (67-69).

"Un aspecto importante de esta literatura es la tradición doble en que se inserta, dos tradiciones distintas que se han complementado: la oralidad ancestral y la escritura occidental" (Carrasco, 2014: 115). De esta transmigración de las lenguas nacería el humor más irreverente, genialmente empleado por Graciela Huinao y que pone nuevamente en jaque la lectura 
intercultural. La valoración de este dinamismo en la literatura mapuche actual nos lo recuerda enfáticamente Cristián Antüllangka ${ }^{10}$ : "(Los mapuche) se han asimilado todo el tesoro de la literatura popular española, dijo hace años don Rodolfo Lenz”. En el nivel metadiegético de la novela Desde el fogón de una casa de putas williche encontramos variedad de ül y epew. Huinao adopta las formas de la novela moderna integrando a su estructura las textualidades tradicionales de su propia cultura. Así el humor transmigra entre los aspectos formales de una y otra tradición literaria. Es decir, en la escritura de Huinao, el ingreso de las formas derivadas de la tradición oral mapuche a una estructura occidental como la novela permite también el ingreso de la risa del mapuche, de su particular forma de celebrar, de sentir, de disfrutar y también de burlarse de los poderes que lo oprimen. Guerra (2014: 137) ha señalado, que a través de la confluencia de los relatos de sus personajes, para construir la historia de la narración, Huinao "está rescatando otro aspecto de la cultura mapuche que se refiere a la noción misma de la Historia": historia oral, no fijada en un relato único, sino construida por relatos de experiencias territoriales diversas. Siguiendo la narración de personajes de La reina Isabel cantaba rancheras (Rivera Letelier, 1994), Pichún, Kintún, y cada una de las putas de La trompa de pato, tendrá su turno para lucirse con alguna ingeniosa historia, pero también para coronar de lirismo algún dramático momento: Los cantos tristes: El ül que la Pincoya, la regenta de La trompa de pato, llamaba "El canto del jote", por el olor a muerte que dejaba al evocar el exterminio de su pueblo; el mítico canto williche en boca de la Yanki, que evoca el sacrificio de la doncella Millaray para aplacar la erupción del volcán de Chaurakawin; el elegíaco canto de la Culítica, cuya letra habla del genocidio de los pueblos del archipiélago y las mujeres canoeras. Como contrapunto a estos cantos tristes irrumpe el canto pícaro, de tema erótico, que transforma el tono del relato y hace "reír por no llorar" al lector que desde el inicio de la narración se ve subsumido en una reunión o junta de voces que hablan de la historia del despojo de su pueblo, de los asesinatos y de la diáspora de las familias williche que fueron ahuyentadas desde los ricos valles del interior hasta la periferia del naciente pueblo de Rahue.

${ }^{10}$ En el prólogo a Cuentos del olvido/ Ngoyüntungeychi puke epew (Antullangka, 2009), y que se inicia precisamente con un epew humorístico; La comadre zorra. 
La risa implica de por sí una victoria contra el miedo, un acto de libertad por el cual el débil capta el punto débil del fuerte, su talón de Aquiles, y dispara hacia él sus dardos. Se presenta así como una visión diferente del mundo, una contracultura que toma a la vida como algo siempre abierto, inacabado, a lo que ningún discurso, ninguna institución, puede en verdad fijar. Ni siquiera calla ante la muerte y la desgracia, a cuyo encuentro sale para impedir que se coagule la tragedia y cunda un llanto sin formas de compensación emocional (Colombres, 1997: 313).

Desde el fogón de una casa de putas williche es una contra-fundación simbólica de la ciudad, una alegoría, que esgrime la memoria oculta por la historia oficial de los hombres y mujeres que desposeídos, arrojados de su propia tierra llegaron a conformar un bastión de fortaleza para sobrevivir la miseria y el dolor de haber perdido a sus padres, a sus madres y a sus hijos en una guerra desigual. El humor permite al lector tomar distancia frente a los crudos hechos que narra la novela. Su presencia, a la vez, confirma la fidelidad de Huinao hacia aspectos centrales de la vitalidad creativa de su cultura, vitalidad que se ha desarrollado en el constante dinamismo de las relaciones interculturales.

En la novela, el humor de tema erótico se despliega traspasando las fronteras culturales, esa es su característica principal, representada en la unión amorosa del gringo Laukao ${ }^{11}$ y la Guatipota una "pareja intercultural": " $\mathrm{Pa}$ ' entrar en calentura/ con látigo de cochayuyo/ la Guatipota al laukao le aforra/ y él en vez de llorar/ como chancho en barro la goza/ hoza, hoza, hoza..." (92)

Virginia Vidal ${ }^{12}$ señala: "En el relato se conjugan vida, experiencias, duelos y alegrías, mucho humor con peculiar síntesis y un lenguaje despojado que permite a Huinao llamar las cosas por su nombre sin el menor rodeo”... "A los instrumentos originarios se van sumando la guitarra y las maracas (percusión). La fiesta no da tregua. Se mezclan canto williche y wingka, se componen canciones, algunas de incomparable picardía como "Zorras con zorras se daban”. Sin duda es este canto citado por Vidal la expresión

11 "Laukao: chancho despellejado con agua hirviendo, después de muerto". (Nota al pie, 91).

${ }^{12}$ En Desde el fogón de una casa de putas williche. Disponible en http://virginia-vidal. com/publicados/ensayos/article_406.shtml 
humorística más desenfadada de la novela. En sus presentaciones públicas, Huinao suele leerlo, no cantarlo, dándole una entonación rítmica de irreverente sugestión a su interpretación. Me permito citar el texto:

Sin duda el caballito de batalla de Kintun "Zorras con zorras se daban"... "una canción que a ritmo de choikepurrün, este originario cantautor riendo cantaba: Por el camino viejo/ orillando la quebrá./ Por el amor de un zorro viejo/ vide dos zorras peliando/ las vide pelaindo pará:/ Zorras con zorras se daban/ la zorrita guac, guac/ la zorrúa guac, guac./ El zorrón desde lejos la miraba./ Se mordían/ se olfateaban./ A muerte/ las dos zorras se pescaban. /El zorrón se lamentaba guac, guac. /Zorras con zorras se daban..." "El puterío enloquecía con estas canciones, simulaban ser zorras peleando en medio de la sala y los williche animando la gresca simulada: guac, guac, a las zorras con sus voces azuzaban (66).

Sabemos por Javier Milanca ${ }^{13}$ que "Zorras con zorras" es un canto pícaro que aún resuena en la memoria de los williche: "En lo personal es grato recordar una canción de pegajosos estribillos que mi abuelo cantaba y repetía con picarona risa: '... Y zorra con zorra se daban'... que mi abuelo recordaba con cariño a lo mejor de alguna estadía suya en una casa de putas williche”. Expresiones propias de la elocuencia popular, en el seno de la matriz cultural mapuche (Caniuqueo, 2011), integran formas artísticas traídas por soldados, comerciantes y cautivas, y también por los mapuche que fueron raptados por los chilenos como "prenda de paz"; y difundidas por los oficiantes de juglares de la época, poetas populares y cantores, que sin duda se han fundido con expresiones más antiguas del baile erótico mapuche, como pudieron haber sido los bailes denominados "nomir nomir purrun, peraf y patin" (Guevara, 1903: 229) o el "hueilpurrun" (Núñez de Pineda y Bascuñán, 2001 [16631673]: 424).

Huinao sitúa el humor en el centro de la hibridez textual (Carrasco, 2010) y en el centro de su poética, exaltando la vitalidad y el dinamismo del lenguaje literario. El humor releva la vitalidad expresiva del mapuche, es comunicación de un sentimiento de proyección de la vida a través de la alegría, la sonrisa, la risa, la carcajada; asumida desde la resiliencia y el

${ }^{13}$ En http://www.futawillipamu.org/Llitu/Desde-el-fogon-de-una-casa-de-putas-williche-de-Graciela-Huinao-Por-Javier-Milanca.html. 
empoderamiento lingüístico, en toda su complejidad: o como escribe Aniñir cuando comenta ${ }^{14}$ el libro Xampurria de Milanca, otro libro cuyo particular sentido del humor vale la pena analizar: "Para qué andamos con cosas: hoy en toda la tierra, con la fuerza del tiempo, se deviene en una transculturación que, más que debilitar la esencia de los pueblos, la enriquece".

\section{Referencias}

Aillapán, L. (2007 [2003]). Üñumche. Hombre Pájaro. Mapudungun-Castellano. Santiago, Chile: Pehuén.

Aniñir, D. (2008). Haykuche. Santiago, Chile: Segunda Bienal de Arte Indígena. . (2009). Mapurbe, venganza raíz. Santiago, Chile: Pehuén. . (2014). Guitranalwe. Santiago de Chile: Quimantú.

Antipán, M. (1997). Cuentos de un mapuche. Santiago, Chile: Ediciones Mundo. Antüllangka, C. (2009). Cuentos del olvido/ Ngoyüntungeychi puke epew. Versión mapunchezüngun por Víctor Cifuentes Palacios. Región de los Ríos, Chile: Artes sanas Kutral we.

Ayenao, P. (2015). Memoria de la carne. Valparaíso, Chile: Bogavantes Ediciones.

Bajtín, M. (2003). La cultura popular en la edad media y el renacimiento. Madrid: Alianza Editorial.

Bergson, H. (2016). La risa. Ensayo sobre el significado de lo cómico. Santiago de Chile: Lom.

Caniuqueo, S. (2011). Reflexiones sobre el uso de la cultura como matriz cultural mapuche en el caso Mapuche. Algunas notas introductorias de principios del siglo XX. Cuadernos interculturales 17, 73-97. Viña del Mar, Chile: Universidad de Playa Ancha.

Carrasco, I. (2000). Poetas mapuches en la literatura chilena. Estudios Filológicos, 35, 139-149.

. (2010). Cherruve... ¿Primera novela mapuche?... Lengua y literatura mapuche, 14, 27-36.

. (2014). La construcción de la literatura mapuche. Revista canadiense de estudios hispánicos, 39, vol. I, 105-121.

Colipán, B. (2005). Arco de interrogaciones. Santiago, Chile: Lom.

Colombres, A. (1997). Celebración del lenguaje: hacia una teoría intercultural de la literatura. Buenos Aires: Ediciones del Sol, S.R.L.

Díaz, A. (2006 [1907]). Parlamento de Coz Coz. Valdivia, Chile: Ediciones Ser Indígena.

${ }^{14}$ Comentario en la contratapa de Xampurria, somos del lof de los que no tiene lof (Milanca, 2015). 
Durán, T; Catriquir, D. (2007). El nombre personal en la sociedad mapunche. Implicaciones étnicas y sociales. En: Duran, T; Catriquir, D; Hernández, A. Patrimonio cultural mapunche. Derechos Sociales y Patrimonio Institucional Mapunche. Volumen III, 377-394. Temuco, Chile: Editorial UC Temuco.

Fuentealba Millaguir, R. (2008). Cherrufe. La bola de fuego (novela mapuche). Valdivia: Gobierno Regional de los Lagos.

García, M. (2011). La actual narrativa mapuche: Testimonio, memoria y "repetición”. Lengua y literatura mapuche, 15, 131-144.

Guerra, L. (2014). La ciudad ajena: Subjetividades de origen mapuche en el espacio urbano. Santiago, Chile: Ceibo.

Guevara, T. (1903). Las últimas familias i costumbres araucanas (Tomo VII de la serie). Santiago, Chile: Imprenta, Litografía y encuadernación Barcelona. Rescatado de Memoria Chilena, http://www.memoriachilena.cl/602/w3article-8187.html

Huaiquilaf, M. (2006). El funeral del último cacique y otros relatos. Santiago, Chile: La Calabaza del Diablo.

. (2016). Receta para engendrar un varón. Santiago, Chile: Rakizuam.

Huenún, J. (1999) Ceremonias. Santiago, Chile: Editorial Universidad de Santiago.

Huinao, G. (2006). En Falabella, S; Huinao, G. y Ramsay, A. (Editoras), Hilando en la memoria. Siete mujeres mapuche/poesía. Santiago, Chile: Cuarto Propio.

. (2009a). Walinto. Santiago, Chile: Cuarto Propio.

. (2009b). En Falabella, S.; Huinao, G. y Miranda, R. (Editoras), Hilando

la memoria II 14 mujeres mapuche /poesía. Santiago, Chile: Cuarto Propio. . (2010). Desde el fogón de una casa de putas williche. Osorno, Unidad de cultura y educación CONADI, Dirección Regional de Osorno. Colección Chaurakawin $\mathrm{N}^{\circ} 6$.

. (2014 [2003]). La nieta del brujo. Seis relatos williche. Santiago, Chile: Ediciones Caballo de Mar. . (2015). Katrilef, hija de un ülmen williche. Santiago, Chile.

Manquilef, M. (2006 [1911]). Comentarios del pueblo araucano (La faz social). Valdivia, Chile: Serindígena Ediciones.

Mansilla, S. (2006 [2001]). Identidades culturales en crisis: versiones y perversiones sobre nosotros y los otros. Versión electrónica Buque de Arte, Ed. Sergio Mansilla. http://sergiomansilla.com, revisado 22/12/2016.

Marileo, A. (2007). Cosmovisión mapuche. Consideraciones para el sistema de Educación mapuche. Temuco, Chile: Gedes Ltda.

Marimán, P. (2006). Los mapuche antes de la conquista militar chileno-argentina. En Marimán, P.; Caniuqueo, S.; Millalén, J; Levil, R. i...Escucha, winka...! Cuatro ensayos de Historia Nacional Mapuche y un epílogo sobre el futuro (pp. 53-126). Santiago, Chile: Lom Ediciones. 
Milanca, J. (2015). Xampurria. Somos del lof de los que no tienen lof. Santiago, Chile: Pehuén.

"Desde el fogón de una casa de putas williche”. Por Javier Milanca. Periódico virtual futawillimapu.org, disponible en http://www.futawillipamu.org/ Llitu/Desde-el-fogon-de-una-casa-de-putas-williche-de-Graciela-HuinaoPor-Javier-Milanca.html. Revisado 22/12/2016.

Nahuelquín, M. (s/f). Cantos de libertad de una mujer mapuche en Valparaíso. Valparaíso, Chile: La Cáfila.

Núñez de Pineda y Bascuñán, F. (2001 [1663-1673]). Cautiverio Feliz. Edición crítica de Mario Ferreccio Podestá y Raissa Kordic Riquelme. Biblioteca Antigua Chilena. Santiago, Chile: Ril Editores.

Panchillo, M. (2010). Por causas del imperio. En Memoria poética. Reescrituras de la Araucana (384-397). Luz Ángela Martínez y Jaime Luis Huenún (compiladores). Santiago, Chile: Editorial Cuarto Propio.

Quevedo, F. (2000). La tristeza del chileno. Santiago, Chile: Mosquito comunicaciones.

Rivera Letelier, H. (1994). La reina Isabel cantaba rancheras. Santiago, Chile: Editorial Planeta.

Rubio, R. (2013). The importance of poetry as a didactic and Political Tool Poems by Three Mapuche Poets. eScholarship, Series World Culture Graduate Student, Conference 2013.Universidad de California. Disponible en http:// escholarship.org/uc/Item/1ob2m6qj. Revisado 22/12/2016.

Salas, A. (2006). El mapuche o araucano. Santiago, Chile: Centro de Estudios Públicos.

Salinas, M. (2010). La risa de Gabriela Mistral. Una historia cultural del humor en Chile e Iberoamérica. Santiago, Chile: Lom Ediciones.

Vidal, V. Desde el fogón de una casa de putas williche. Disponible en http://virginia-vidal.com/publicados/ensayos/article_406.shtml. Revisado 22/12/16. 